This is the final peer-reviewed accepted manuscript of:

Candela, G., Castellani, M., Pattitoni, P. et al. On Rosen's and Adler's hypotheses in the modern and contemporary visual art market. Empir Econ 51, 415-437 (2016). https://doi.org/10.1007/s00181-015-1002-3.

The final published version is available online at: https://doi.org/10.1007/s00181$\underline{015-1002-3}$

Rights / License:

The terms and conditions for the reuse of this version of the manuscript are specified in the publishing policy. For all terms of use and more information see the publisher's website.

This item was downloaded from IRIS Università di Bologna (https://cris.unibo.it/)

When citing, please refer to the published version. 


\title{
On Rosen's and Adler's hypotheses in the modern and contemporary visual art market
}

\author{
Guido Candela* $^{*}$ Massimiliano Castellani $^{\dagger} \cdot$ Pierpaolo Pattitoni $^{\ddagger}$ - F. Marta L. Di \\ Lascio $^{\S}$
}

\begin{abstract}
Using a unique hand collected dataset, comprising all artwork sales in Italy between 2006 and 2010, we test Rosen's and Adler's hypotheses in the modern and contemporary visual art market. We extract our measures of artist talent and fame from a set of observable artist-specific variables by means of a factor analysis and estimate the elasticities of income with respect to talent and fame. Consistent with Rosen's and Adler's hypotheses, our results suggest a convex relationship between income and talent and a linear relationship between income fame. Using SUR models to evaluate the effects of artist talent and fame on the average trade prices and number of sales, we find that the number of artwork sales is the main 'channel' through which talent and fame influence income. Copula models provide additional insights on the nature of the conditional dependence relationship between average prices and number of sales. Poolability tests suggest a single model of artist income applies to all artists in our dataset whether their works are generally traded in auction houses or galleries so it is not necessary to specify different models. Finally, quantile regressions reveal that artists in low income quantiles are not superstars, Rosen's hypothesis holds only above the median income and fame plays no role for low income quantiles.
\end{abstract}

Keywords Rosen's theory $\cdot$ Adler's theory $\cdot$ superstar $\cdot$ talent $\cdot$ fame $\cdot$ income

JEL Classification $\mathrm{Z} 11 \cdot \mathrm{C} 10 \cdot \mathrm{C} 30$

Acknowledgments We thank two anonymous reviewers for their suggestions. The last author acknowledges the support of the Free University of Bozen-Bolzano, Faculty of Economics and Management via the project "Multivariate analysis techniques based on copula function".

\footnotetext{
* Department of Economics, University of Bologna, Italy. Email: guido.candela@unibo.it

$\dagger$ Department of Economics, University of Bologna and Rimini Centre for Economic Analysis (RCEA), Italy. Email: m.castellani@unibo.it

* Department of Management, University of Bologna and Rimini Centre for Economic Analysis (RCEA), Italy. Email: pierpaolo.pattitoni@unibo.it

$\S$ School of Economics and Management, Free University of Bozen-Bolzano, Italy. Email: marta.dilascio@unibz.it
} 


\section{Introduction}

In the modern and contemporary visual art market, a small number of artists earn a very high income and emerge as superstars (Thompson 2010; Beatrice 2012). Consider the example of Lucio Fontana. During the period 1999-2012, Lucio Fontana was traded about 2,500 times in the major international art auctions, with an average price of about $€ 200,000$. Lucio Fontana generated revenues of about $€ 500$ million.

Two theories - developed to analyze the phenomenon of a superstar in general (Baumol and Throsby 2012) - may explain the specific phenomenon of superstars in the modern and contemporary visual art market: (1) Rosen's (1981) and (2) Adler's (1985) theories (for a description of Rosen's and Adler's theories see MacDonald 1988, Ginsburgh and Throsby 2006, Towse 2013).

(1) Rosen's (1981) theory implies that a variation of talent leads to a more than proportional variation in income, i.e., income is convex in talent (in our empirical setup we call this implication of Rosen's theory 'Rosen's hypothesis').

(2) Adler's (1985) theory builds on Rosen's to show that income also increases with fame (in our empirical setup we call this implication of Adler's theory 'Adler's hypothesis').

Empirical studies testing Rosen's and/or Adler's hypotheses have provided mixed results. ${ }^{1}$ Most present evidence for mass markets such as music (Hamlen 1991; Hamlen 1994; Crain and Tollison 2002; Krueger 2005; Filimon et al. 2011) and sports (Lucifora and Simmons 2003; Franck and Nüesch 2008; Lehmann and Schulze 2008; Franck and Nüesch 2012, Bryson et al. 2014) ${ }^{2}$, while empirical studies on the visual art market are still scarce since testing the theories of superstar formation would require a perfect (or nearly perfect) reproducibility of artworks. Nevertheless, it is possible to test these theories if we assume that

\footnotetext{
${ }^{1}$ By the expressions 'Rosen's hypothesis' and 'Adler's hypothesis', we do not mean the theoretical assumptions underlying 'Rosen's theory' and 'Adler's theory', but their implications to be tested empirically. As Filimon et al. (2011) note, the main problem in testing Rosen's and Adler's hypotheses is due to the difficulty to measuring artist talent and fame.

${ }^{2}$ Ehrmann et al. (2009) provide an interesting analysis of superstar effects in the 'deep-pocket' market of gastronomy (deluxe cuisine) in German quality restaurants. The modern and contemporary visual art market also belongs to this kind of market where a small number of consumers are willing to pay an extra premium to the stars. The majority of existing research presents evidence for mass markets (e.g., entertainment industry) rather than these 'deep-pocket' markets.
} 
modern and contemporary visual art buyers are not interested in artworks per se - which are irreproducible by definition - but rather in artists in $s e .^{3}$

To test both Rosen's and Adler's hypotheses in the modern and contemporary visual art market, we assume that buyers of visual art are actually purchasing artist signatures, styles, or iconographies ${ }^{4}$ - which are infinitely reproducible at no additional cost. This assumption relies on the concept of artist fixed effects which is typical in hedonic models (Rengers and Velthuis 2002; Hellmanzik 2009; Canals-Cerdà 2012; Etro and Pagani 2013). According to Hellmanzik (2009), artist fixed effects 'account for any individual specific characteristics that might explain prices', which implies the price heterogeneity is lower within artist than between artists. Artist signature is certainly not the only important aspect to consider in the art market, but it is important enough to select the artist as the unit of observation in empirical analyses. Excluding masterpieces, the artist's signature plays a similar role to a brand: while each artwork is inherently a unique item, the signature allows us to recreate by aggregating data at artist level the ideal 'reproducibility condition' that is at the heart of theories of superstar formation.

We examine the modern and contemporary visual art market using a unique hand collected dataset of modern and contemporary visual artists, comprising all artwork sales occurring in Italy between 2006 and 2010 (Castellani et al. 2012). In addition to Lucio Fontana, our dataset contains artists generally recognized as talented and popular including Pablo Picasso, Salvador Dalì, Piero Manzoni, Giorgio Morandi and Giorgio de Chirico.

As a first step, we propose a model of artist factor income as a function of talent and fame and state Rosen's and Adler's hypotheses in terms of talent and fame-elasticities. Then, we proxy artist income by the total revenue in the secondary art market, taking advantage of

\footnotetext{
${ }^{3}$ Collectors often refer to pieces of art using the names of the artists and collections are often remembered for the number of pieces by a specific artist, e.g., the Agnelli collection is remembered because it includes Picasso, Renoir, Canaletto, Matisse and Canova. Cultural tourists are known to select museums that host exhibits by a particular artist rather than simply because they exhibit a specific piece of art (notable masterpiece exceptions aside). For this reason, tourist guides often highlight and promote museums solely through the names of the artists on exhibit.

${ }^{4}$ Thompson (2010) provides a striking example to support our assumption. In February 2007, Adrian Anthony Gill, a well-known journalist for the London Sunday Times, offered Christie's an old portrait of Stalin, by an anonymous artist, which he had purchased for $£ 200$. Christie's rejected the portrait, since they did not deal in dictator portraits. Gill asked Hirst to paint a red nose on his Stalin portrait and Hirst signed the portrait after painting it. Christie's accepted the modified portrait with Hirst's signature, and it sold for $£ 140,000$. Artist's shit by Manzoni is another good example: buyers are not really interested in Manzoni's feces but in his signature. The same reasoning applies to Duchamp's Fountain. Another example is the Andy Warhol flyers mailed to collectors for the release of his 'Mao' portfolio of ten screen-prints. Warhol signed some of these flyers during his first showing and today, these flyers are traded in auction sales.
} 
the fact that in Italy (similar to other European countries) when an artwork is resold in the secondary art market by professional intermediaries, artists (or their descendants) are entitled to a royalty arising from the Artist's Resale Right (ARR hereinafter). A factor analysis allows us to extract our measures of artist talent and fame from a set of observable artist-specific variables related to familiar environment, eclecticism, studies, death event and the number of years an artist (or her artwork) is present in the visual art market. Then, we estimate talent and fame-elasticities of income via regression analysis and find evidence supporting Rosen's and Adler's hypotheses for the art sector.

To separate the relative importance of average price and number of sales on artist income, we evaluate the effects of talent and fame on the average price and the number of artwork sales (the product of these two variables is equal to artist income). Findings suggest that artist income is primarily affected by talent and fame through the number of artwork sales. We use copula models to investigate the nature and the strength of the conditional dependence relationship between average prices and number of artwork sales in order to better understand how a shock on prices affects number of sales and vice versa. The results of this analysis show that average price and number of sales exhibit a positive and asymmetric dependence relationship.

Finally, to determine if different models should be estimated for artists primarily traded in auction houses as opposed to galleries, we perform a poolability test to check whether a single model of artist income applies to all artists. Our results indicate that a single encompassing model of artist income applies to all artists in our dataset and that Rosen's and Adler's hypotheses also hold true at a disaggregated level. As an additional analysis, we test whether talent and fame-elasticities are uniform across income quantiles and, consistent with Rosen, find that in the lower part of the artist income distribution artists are not superstars (Rosen's hypothesis holds only beyond a median level of income) and fame does not play a role.

The paper is organized as follows. In Section 2, we present our model. In Section 3, we describe our dataset. In section 4, we present our empirical analysis. In Section 5, we summarize the main results of our analysis. 


\section{Model}

We use a Cobb-Douglas function to model the artist factor income as a function of talent and fame,

$$
Y_{i}=A_{i} T_{i}^{\tau} F_{i}^{\varphi}, \quad i=1, \ldots, I
$$

where $Y_{i}, T_{i}$, and $F_{i}$ are artist $i$ income, talent, and fame, $A_{i}$ captures artist heterogeneity, and $\tau$ and $\varphi$ are talent and fame-elasticities (all variables are assumed to be positive).

(1) Rosen's hypothesis requires $\partial Y_{i} / \partial T_{i}>0$ and $\partial^{2} Y_{i} / \partial T_{i}^{2}>0$, which in Equation 1 is equivalent to $\tau>1$.

(2) Adler's hypothesis requires $\partial Y_{i} / \partial F_{i}>0$, which in Equation 1 is equivalent to $\varphi>0$.

In logarithmic form, Equation 1 becomes

$$
y_{i}=a_{i}+\tau t_{i}+\varphi f_{i}
$$

where we defined $y_{i} \equiv \ln \left(Y_{i}\right)$, and the same for $a_{i}, t_{i}$, and $f_{i}$.

In Equation 2, we can decompose $a_{i}$ as

$$
a_{i}=\alpha+\mathbf{c}_{i}{ }^{\prime} \kappa+\varepsilon_{i}
$$

where $\alpha$ is a constant, $\mathbf{c}_{i}$ is a column vector of control variables that influence artist heterogeneity, $\boldsymbol{\kappa}$ is a column vector of coefficients, and $\varepsilon_{i}$ is an error term with a conditional mean of zero.

Combining Equations 2 and 3, we test Rosen's and Adler's hypotheses using the following empirical model 


$$
y_{i}=\alpha+\not t_{i}+\varphi f_{i}+\mathbf{c}_{i}{ }^{\prime} \boldsymbol{\kappa}+\varepsilon_{i}
$$

where coefficients can be estimated by Ordinary Least Squares (OLS).

Since artist income is the product of average price, $P_{i}$, and the number of artwork sales, $N_{i}$, we can evaluate the effects of talent and fame on $P_{i}$ and $N_{i}$ separately to understand their relative importance. Indicating the logarithm of $P_{i}$ and $N_{i}$ with $p_{i}$ and $n_{i}$, we can split, without loss of generality (since null coefficients are admitted), Equation 4 into two equations

$$
\begin{gathered}
p_{i}=\alpha_{p}+\tau_{p} t_{i}+\varphi_{p} f_{i}+\mathbf{c}_{i}{ }^{\prime} \boldsymbol{\kappa}_{p}+\varepsilon_{p i} \\
n_{i}=\alpha_{n}+\tau_{n} t_{i}+\varphi_{n} f_{i}+\mathbf{c}_{i}{ }^{\prime} \boldsymbol{\kappa}_{n}+\varepsilon_{n i}
\end{gathered}
$$

Using the product rule of logarithm, $y_{i}=p_{i}+n_{i}$ and so $\alpha=\alpha_{p}+\alpha_{n}, \tau=\tau_{p}+\tau_{n}$, $\varphi=\varphi_{p}+\varphi_{n}, \mathbf{\kappa}=\boldsymbol{\kappa}_{p}+\boldsymbol{\kappa}_{n}$, and $\varepsilon_{i}=\varepsilon_{p i}+\varepsilon_{n i}$.

If we stack the $I$ equations (one for each artist) into a system, then we can write Equations $5 \mathrm{a}$ and $5 \mathrm{~b}$ as

$$
\begin{gathered}
\mathbf{p}=\alpha_{p}+\tau_{p} \mathbf{t}+\varphi_{p} \mathbf{f}+\mathbf{C} \boldsymbol{\kappa}_{p}+\boldsymbol{\varepsilon}_{p}=\left[\begin{array}{lll}
\mathbf{t} & \mathbf{f} & \mathbf{C}
\end{array}\right]\left[\begin{array}{c}
\tau_{p} \\
\varphi_{p} \\
\boldsymbol{\kappa}_{p}
\end{array}\right]+\boldsymbol{\varepsilon}_{p}=\mathbf{X} \boldsymbol{\beta}_{p}+\boldsymbol{\varepsilon}_{p} \\
\mathbf{n}=\alpha_{n}+\tau_{n} \mathbf{t}+\varphi_{n} \mathbf{f}+\mathbf{C} \boldsymbol{\kappa}_{n}+\boldsymbol{\varepsilon}_{n}=\left[\begin{array}{lll}
\mathbf{t} & \mathbf{f} & \mathbf{C}
\end{array}\right]\left[\begin{array}{c}
\tau_{n} \\
\varphi_{n} \\
\boldsymbol{\kappa}_{n}
\end{array}\right]+\boldsymbol{\varepsilon}_{n}=\mathbf{X} \boldsymbol{\beta}_{n}+\boldsymbol{\varepsilon}_{n}
\end{gathered}
$$

The final system consisting of the two systems of Equations 6a and $6 \mathrm{~b}$ (for a total of $2 I$ equations) takes the form 


$$
\left[\begin{array}{l}
\mathbf{p} \\
\mathbf{n}
\end{array}\right]=\left[\begin{array}{cc}
\mathbf{X} & \mathbf{0} \\
\mathbf{0} & \mathbf{X}
\end{array}\right]\left[\begin{array}{l}
\boldsymbol{\beta}_{p} \\
\boldsymbol{\beta}_{n}
\end{array}\right]+\left[\begin{array}{l}
\boldsymbol{\varepsilon}_{p} \\
\boldsymbol{\varepsilon}_{n}
\end{array}\right]=\mathbf{X} \boldsymbol{\beta}+\boldsymbol{\varepsilon}
$$

We can assume the following properties for $\boldsymbol{\varepsilon}$

$$
\mathrm{E}(\boldsymbol{\varepsilon} \mid \mathbf{X})=\mathbf{0}, \quad \operatorname{Var}(\boldsymbol{\varepsilon} \mid \mathbf{X})=\left[\begin{array}{cc}
\sigma_{p}^{2} & \sigma_{p n} \\
\sigma_{p n} & \sigma_{n}^{2}
\end{array}\right] \otimes \mathbf{I}_{I}=\boldsymbol{\Sigma} \otimes \mathbf{I}_{I}
$$

where $\mathbf{I}_{I}$ is the $I$-dimensional identity matrix. Thus, for any given artist, this model allows for arbitrary cross-correlation between the $p_{i}$ and $n_{i}$ equations.

Considering the properties of $\boldsymbol{\varepsilon}$ in Equation 8, we can estimate the coefficients of Equation 7 by Feasible Generalized Least Squares (FGLS) in a SUR model (Zellner 1962) a generalization of a linear regression model consisting of several (possibly cross-correlated) regression equations. Since Equations $6 \mathrm{a}$ and $6 \mathrm{~b}$ contain exactly the same set of regressors, FGLS and equation-by-equation OLS estimates are numerically equivalent (Greene 2011). Even in such a case, however, the SUR model is useful to perform joint tests.

The SUR model takes into account the potential cross-correlation between $p_{i}$ and $n_{i}$ by providing an estimate of all the parameters in $\Sigma$, i.e., the conditional variance matrix of the system of equations. However, the system in Equation 7 does not provide a structural relationship between the two equations (i.e., the dependent variable of one equation never appears among the covariates of the other equation). Equations $p_{i}$ and $n_{i}$ are still linked together through $\sigma_{p n}$.

\section{Data}

The sample, based on a unique hand-collected dataset of artist-specific information on all modern and contemporary visual artists whose artworks were traded in Italy between 2006 
and 2010 (Castellani et al. 2012), ${ }^{5}$ consists of 514 professional visual artists who are heterogeneous in terms of income, talent, fame and other artist-specific characteristics (e.g. gender, nationality, age etc.). Only sales over $€ 3,000$ by artists who died less than 70 years ago are considered, as these are necessary conditions for royalties to be paid under the ARR.

Examining the ARR archives of the SIAE (Società Italiana degli Autori e degli Editori) - the multipurpose-society which handles royalty disbursement for artists - we collected all available information (artist, price, trade) about the 22,921 sales involving professional intermediaries that occurred in Italy in the five-year period 2006-2010. The total number of professional visual artists with available information is 514. For each artist we collected additional information from art information providers available on the web (artprice.com, artnet.com, arsvalue.com and artfacts.net) and use secondary market trades to make inferences on the income of these 514 artists.

In Italy (as in most European Countries), when artwork is resold in the secondary art market by auction houses or art galleries, the SIAE is entitled by law to collect and distribute royalties to the artist or her descendants (Candela and Scorcu 2012). For this reason, even if the artist is not directly involved in the transaction, the sum of these royalties, which is proportional to revenue generated by auctions and art gallery sales is the artist's 'actual' income in the secondary market. We call the total revenue in the secondary market 'potential' income to reflect the fact that if the royalty fees were equal to one, revenue would equal the artist's income.

In principle, to fully explain the phenomenon of superstar formation, both secondary and primary market revenues should be considered. However, since multiple trades per artist are available in the secondary market, an artist's secondary market income distribution tends to overlap her total income distribution. As a result, the primary market trades become quasi negligible. This assumption holds true when, in the five-year period we consider, the primary market revenues are zero. During this period, primary market revenues are zero for "inactive" artists that, by definition, do no create and/or sell new artworks in the primary market. In addition, the primary market revenues are negligible for artists whose trades in the secondary

\footnotetext{
${ }^{5}$ According to the Tefaf report 2010 (the most relevant considering the time window of our study), on a worldwide scale, Italy is fifth (third in Europe) in terms of art auction turnover and experienced an increase in the art market turnover of about $60.2 \%$ in the period 1998-2008 (the highest worldwide percentage).
} 
market represent the largest part of their trades (highly traded artists). ${ }^{6}$ Finally, distinguishing between superstars and non-stars in short time period is easier in the secondary market than in the primary market. Moreover, since trades per artist are typically non frequent in the primary market, it is challenge to distinguish superstars from non-stars when the observational period is short (like in our analysis).

We use three groups of variables in our models: (1) response variables, (2) variables that could be associated with artist talent and/or fame, and (3) control variables. Note that to avoid a proliferation of notation we indicate empirical variables using the same notation of theoretical variables. Table 1 shows descriptive statistics for each variable.

\section{Group 1 - Response variables}

- $\quad y$ is the logarithm of each artist's potential income. Since an artist's actual income is proportional to her potential income, coefficient estimates in all our models (with the exception of the constants) are unaffected by the choice of using potential income instead of actual income as a dependent variable.

- $\quad p$ is the logarithm of the average price of artwork sales.

- $\quad n$ is the logarithm of the number of artwork sales.

\section{Group 2 - Variables that could be associated with artist talent and/or fame}

- deceased is a dummy variable equal to 1 if the artist is deceased. We expect this variable could be associated with fame, since an artist's death is a crucial event that influences both the supply and the demand of that artist's artworks (Ekelund Jr et al. 2000; Ursprung and Wiermann 2011). In our dataset, there are 26 cases where the year of death is between 2006 and 2010. This fact could in principle affect our results. However, unreported robustness checks reveal that the results are not significantly affected when these observations are excluded from the analysis.

\footnotetext{
${ }^{6}$ Deceased artists are $41.28 \%$ of our sample. Moreover, old artists are the largest part of our sample (only $10 \%$ of the living artists are less than 40 years old). We can reasonably assume that old artists are inactive in the primary market or, at least, less active than young artists. In addition, most of the artists in our sample are highly traded artists (more than 10 trades). Only $2.33 \%$ of artists are simultaneously living, young and non-highly traded. Only for these artists, our assumption is less likely to be invalid. However, our findings are not altered if we exclude these artists from our sample. Results are not reported to save space, but are available from the authors on request.
} 
- descendant is a dummy variable equal to 1 if the artist is of artist descendant. We expect this variable could be associated with talent since artistic environments stimulate creativity.

- existence is the difference between year 2010 and the artist year of birth. We expect existence to be associated with fame. ${ }^{7}$ Based on the assumption that, on average, artists start producing/selling at almost the same age, this variable is related to the number of years that an artist (or her artwork) is present in the visual art market. While not fully realistic, this is an assumption that we maintain as it considerably simplifies the data gathering process (information is not readily available on the exact year each artist exhibited/sold her first artwork). In principle, descendant could also be correlated with fame and existence with talent. The factor analysis will shed light on the actual correlation structure between these two variables.

- muforms is a dummy variable equal to 1 if the artist does not specialize in a single form of art (such as painting), but in more than one form of art. Since muforms could be considered a proxy for an artist's eclecticism, we expect this variable to be associated with talent.

- study is a dummy variable equal to 1 if the artist has studied art. This is the observable component of an artist's human capital which is accumulated by education and, thus, we expect this variable to be associated with talent.

\section{Group 3 - Control variables}

- gallery is the number of trades mediated by art galleries (rather than auction houses) over the total number of trades.

- male is a dummy variable equal to 1 if the artist is male.

- sculpture is a dummy variable equal to 1 if the artist is considered mainly as a sculptor in our data sources.

- world is a dummy variable equal to 1 if the artist is not Italian. While all trades took place in Italy, not all artists in our dataset are Italian.

\footnotetext{
${ }^{7}$ Choosing the year of birth or any other year as a reference point (e.g. 30 years) has no effect on the results since this variable is used in a factor analysis and factor analyses are based on correlation matrices that, by definition, are invariant to linear transformation.
} 
- period is a set of six control dummies indicating the artistic period of the artist. To assign an artist to a period, we consider the historical period of development for the artistic movement to which she belongs (e.g., all Futurists are assigned to the artistic period from 1900 to 1925). In the few cases in which an artist claims not to belong to any artistic movement, we inferred the artistic period by adding 30 years to her date of birth.

\section{Empirical analysis}

\subsection{Talent and fame}

In this section, we estimate a linear factor model (Basilevsky 2009), which we use as a statistical technique to determine proxy common factors for talent and fame (to be used in following regression analyses) from deceased, descendant, existence, muforms, and study (Kozbelt 2004; Hagtvedt et al. 2008). Standard factor analysis is based on Pearson's correlation matrices and assumes that the variables are continuous. Since our dataset contains also dichotomous variables, we perform the factor analysis by means of a polychoric correlation matrix (Olsson 1979; Bonett and Price 2005). Table 2 shows the correlation matrix. Note that all variables are positively correlated, with the strongest correlation observed between deceased and existence. ${ }^{8}$

The factor loadings for the promax oblique rotation of the factor axes are shown in Table 3. ${ }^{9}$ Reported factor loadings indicate how each variable is weighted in each factor. To determine the number of factors to be included in the analysis we used the Kaiser rule (all components with eigenvalues under one have been dropped). The resulting number of factors is two which is coherent with our a priori belief of an underlying structure based on two variables, i.e., talent and fame.

Observing the factor loadings, we note that deceased and existence are positively associated with the first factor (the association with the second factor is negligible). For this reason, we propose interpreting this first factor as representing artist fame. Note that we are

\footnotetext{
8 At this stage, inference is not our main concern. We are only performing an explorative analysis of the correlation among variables in this specific sample of data.

${ }^{9}$ We choose the promax rotation because it allows the factors to be correlated: in our application the correlation between the two factors is 0.167 . The average value of the raw residuals of correlations (observed correlations fitted correlations) is -0.090 , evidencing a good fit of the estimated model.
} 
not proposing that death or the simple passage of time 'causes' an increase in fame, but simply that in our dataset several famous artists are deceased and/or their artworks have been present in the market for a long time.

The second factor, descendant, muforms, and study exhibit positive factor loadings. Since these variables are related to the observable component of human capital and ceteris paribus greater human capital implies greater talent, we propose interpreting the second factor as a representation of artist talent (Filer 1990; Throsby 2006; Towse 2006). The key assumption is 'ceteris paribus': if two artists (say A and B) are completely identical in all respects, but A has a higher endowment of human capital than B (say A is more eclectic than B), we can assume that A is more talented than B.

After calculating scoring coefficients for the first and second factor, we obtained $t$ and $f$, and use them as explanatory variables in following regression analyses.

A critical comment on our measures is necessary. Since talent and fame are difficult to measure, defining good proxies for artist talent and fame is also a difficult task. All empirical analyses in our paper are necessarily based on the assumption that, though we cannot perfectly track talent and fame, our measures are at least sufficiently correlated with them. Note that this assumption characterizes most of the studies on Rosen's and Adler's theories.

Our measure of talent is in line with most of the previous studies testing Rosen's hypothesis which also use variables related to human capital to proxy for talent. Even though we are not aware of any example directly pertaining the visual art sector (where studies are still sparse), there are several examples for the music and sport sectors. For example Hamlen (1991) uses the harmonic measurement of an artist's voice as a talent proxy and thus employs a dimension of human capital that can be improved with education. Other examples in the sport sectors include Lucifora and Simmons (2003), Franck and Nüesch (2008), Lehmann and Schulze (2008), and Franck and Nüesch (2012) who use 'outcome' variables such as number of goals, assists, tackles and other performance statistics as talent proxies. With respect to these previous studies, our work contributes to the literature by providing a measure of talent that combines several variables through factor analysis instead of using one variable at a time. 
On the other hand, we understand our measure of fame could seem non-conventional and raise some concerns. Considering that proxies must be chosen for a specific context and not in absolute terms, it is therefore possible that whether or not our fame proxy is a good general proxy, it is still a good enough fame proxy for our specific sample of artists. Even though we maintain this assumption in the following sections, in the "Robustness checks" Section we provide additional analyses using 'more conventional' proxies for fame.

\subsection{Talent, fame, and artist income}

A preliminary analysis on our dataset shows that artist income is highly concentrated (the Gini index of artist income is equal to 0.792), i.e., a small number of artists earn a high income and emerge as a superstar. In this section, we estimate the model in Equation 4 to ascertain if Rosen's and Adler's hypotheses can explain this income concentration.

Table 4 reports estimates of Equation 4. We have estimated two OLS models. Both models include our proxies for talent and fame. While the first model includes all control variables described in Section 3 (see Group 3), the second model includes only the control variables with a p-value less than $0.2 .^{10}$ The results of the two specifications are very similar. ${ }^{11}$ In particular, our results show that artist income is positively affected by talent and fame. Since the estimated talent-elasticity is significantly larger than one, as seen in the reported confidence intervals, we cannot reject Rosen's hypothesis. Furthermore, since the estimated fame-elasticity is positive, we cannot reject Adler's hypothesis either.

A visual representation of the estimated effects of talent and fame on income for the 'representative' (or average) artist is provided in Figure 1 (Candela and Scorcu 1997). In particular, the plot on the left shows that a variation in talent implies a more than proportional variation in income; the plot on the right shows that a variation in fame implies an (approximately) proportional variation in income. Both these effects are coherent with Rosen's and Adler's hypotheses.

\subsection{Average price and number of artwork sales}

\footnotetext{
${ }^{10} \mathrm{We}$ are using a backward-stepwise selection where we choose 0.2 as the significance level for removing a control variable from the model. The removed control variables are male, sculpture, and a couple of artistic period dummies.

${ }^{11}$ Note, however, as the standard errors indicate, the estimates of the second model are slightly more precise than the first model. Since some of the control variables in the first model are non-significant, omitting them in the second model increases the precision of the estimates.
} 
We evaluate the effects of our proxies for talent and fame on the average price and the number of artwork sales separately to test whether the effect of talent and fame on income passes mainly through price or number of sales. The results may help auction houses and galleries in their artist selection mechanisms and pricing strategies. For example, an interesting result would be an asymmetric effect of talent and/or fame on prices and number of sales, indicating the existence of a main 'channel' through which talent and fame influence income.

In Table 5, we present our estimates of Equation 7. Specifically, we have estimated a SUR model. The results show that both $p$ and $n$ are positively affected by $t$ and $f$. Since the coefficients associated with talent in the two equations sum up (by construction) to the estimated elasticity reported in Table 4, we conclude that most of the effect of talent on artist income passes through $n \quad\left(\tau_{n} / \tau=76.41 \%\right)$. A similar result applies to fame $\left(\varphi_{n} / \varphi=75.87 \%\right)$. Therefore, the main channel through which talent and fame influence income is number of sales.

Moreover the conditional correlation between $p$ and $n$ is positive and significant (0.261, p-value $<0.001)$ implying that a positive shock on one equation also positively affects the other equation (and vice versa). This supports our expectation of a dependence relationship between $p$ and $n$.

We can further investigate the nature and the strength of the conditional dependence relationship between $p$ and $n$ in order to better understand how a shock on $p$ affects $n$ and vice versa. Specifically, we use copula models to investigate the dependence relationship between estimated $\varepsilon_{p i}$ and $\varepsilon_{n i}$ (Cherubini et al. 2004; Nelsen 2006; Trivedi and Zimmer 2007)..$^{12}$

We fit several copula models (symmetric, left asymmetric and right asymmetric models) to our data through the so-called inference for margins method (Joe and Xu 1996) in

\footnotetext{
12 The theorem by Sklar (1959) provides the theoretical foundation for using copulas. The probabilistic interpretation of this theorem allows us to write any multivariate cumulative distribution function in terms of two marginal distribution functions and a copula, which describes the dependence relationship between the variables independently from the margins.
} 
a semi-parametric fashion. ${ }^{13}$ We find that a Clayton copula with a significant positive dependence parameter $\theta=0.279$ produces the best fit. ${ }^{14}$ Since the Clayton copula exhibits strong left tail dependence but weak right tail dependence and the parameter is positive, our analysis confirms the results obtained via the SUR model (i.e., a positive relationship between $\varepsilon_{p i}$ and $\varepsilon_{n i}$ ) and adds that the relationship is a lower tail dependency (i.e., $p$ and $n$ are likely to experience extreme low values together and are not likely to simultaneously realize upper tail values).

\subsection{Auction houses vs. galleries}

The results in Table 4 are coherent with both Rosen's and Adler's hypotheses and indicate a single model of artist income is common to all artists in our dataset. However, since auction houses and galleries differ in their artist selection mechanisms and pricing strategies, a distinction could emerge between the models of income determinants for artists prevalently traded in auction houses and artists prevalently traded in galleries, implying different effects of talent and fame on artist income in these two artist subsamples.

In this section, we use a poolability test (Patuelli et al. 2010; Verbeek 2012) with respect to the auction houses/galleries subdivision. This poolability test checks for subsample stability of the estimated coefficients to determine whether a single model (in our case the model in Table 4) applies to all artists in our dataset or if it would be better to specify different models for artists whose works are normally traded in auction houses and artists usually traded in galleries.

Indicating the artists traded in auction houses with the subscript $A$ and the artists traded in galleries with the subscript $G$, our poolability test applied to Equation 4 can produce two results.

(1) If $\left[\begin{array}{lll}\tau_{A} & \varphi_{A} & \boldsymbol{\kappa}_{A}^{\prime}\end{array}\right]=\left[\begin{array}{lll}\tau_{G} & \varphi_{G} & \mathbf{\kappa}_{G}^{\prime}\end{array}\right]$, then a single model of artist income applies to all artists in our dataset.

\footnotetext{
${ }^{13}$ We model marginal probability densities, without making any assumptions on their parametric form by using the empirical cumulative distribution function computed from the residuals under investigation, and the copula parameter $\theta$ through the maximum likelihood function of the copula.

${ }^{14}$ We choose the Clayton copula based on the visual inspection of the scatter plot of probability integral transform of estimated $\varepsilon_{p i}$ and $\varepsilon_{n i}$, the Akaike information criterion, and the Cramèr-von Mises test (Genest et al. 2009). All analyses performed are available from the authors on request.
} 
(2) If $\left[\begin{array}{ccc}\tau_{A} & \varphi_{A} & \boldsymbol{\kappa}_{A}^{\prime}\end{array}\right] \neq\left[\begin{array}{lll}\tau_{G} & \varphi_{G} & \boldsymbol{\kappa}_{G}^{\prime}\end{array}\right]$, then two separated models of artist income need to be estimated for each subsample.

Table 6 shows our estimates of Equation 4, using the variable gallery as a threshold variable to split our sample in two subsamples: the first subsample includes artists prevalently traded in auction houses ( gallery $<0.5$ ); the second subsample includes artists prevalently traded in galleries ( gallery $\geq 0.5$ ). The poolability test reported at the bottom of the table is not significant $(\mathrm{p}$-value $=0.359)$, indicating that the estimated coefficients are stable across the two subsamples, and supports the existence of an encompassing model of artist income determinants. ${ }^{15}$ This result also implies that $\tau_{A}=\tau_{G}$ and $\varphi_{A}=\varphi_{G}$, so the talent and fameelasticities for artists prevalently traded in auction houses are the same as those for artists generally traded in galleries. Furthermore, as the tests on the single coefficients in Table 6 indicate, Rosen's and Adler's hypotheses are supported in both subsamples, i.e., $\tau_{A}=\tau_{G}>1$ and $\varphi_{A}=\varphi_{G}>0$.

\subsection{Low, median, and high artist income}

In the previous sections, we modeled the conditional mean of artist income. However, the effects of our proxies for talent and fame in the lower part of the artist income distribution may differ from the effect of these same variables in the upper part of artist income distribution. As Franck and Nüesch (2008) note, Rosen (but a similar reasoning applies to Adler) defines superstars as high-income artists but does not define any explicit income threshold to distinguish between superstars and non-stars. Studying the characteristics of the conditional distribution of artist income, such as its quantiles, could help identify this threshold.

In this section, we estimate a quantile regression model (Koenker and Hallock 2001; Koenker 2005; Kleiber and Zeileis 2008; Chamarbagwala 2010), in which the conditional quantile function (indexed by the quantile $q$ ) is given by

\footnotetext{
${ }^{15}$ The Gini indexes of the two subsamples are quite similar: the Gini index for auction houses is equal to 0.808 ; the Gini index for galleries is equal to 0.775 . We estimated two SUR models on the two subsamples. Results of these two models are not informative and are not reported.
} 


$$
Q_{y}(q \mid t, f, \mathbf{c})=\alpha+\tau_{q} t_{i}+\varphi_{q} f_{i}+\mathbf{c}_{i}{ }^{\prime} \boldsymbol{\kappa}_{q}
$$

where $Q_{y}(q \mid t, f, \mathbf{c})$ indicates the $q$-quantile of artist income conditional on talent, fame and control variables. We estimate Equation 9 for quantiles 0.25 (low income, $L$ ), 0.5 (median income, $M$ ), and 0.75 (high income, $H$ ) simultaneously by simultaneous-quantile regression.

(1) If $\left[\begin{array}{ll}\tau_{L} & \varphi_{L}\end{array}\right]=\left[\begin{array}{ll}\tau_{M} & \varphi_{M}\end{array}\right]=\left[\begin{array}{ll}\tau_{H} & \varphi_{H}\end{array}\right]$, then talent and fame-elasticities are homogenous across artist income quantiles.

(2) If $\left[\begin{array}{ll}\tau_{L} & \varphi_{L}\end{array}\right] \neq\left[\begin{array}{ll}\tau_{M} & \varphi_{M}\end{array}\right]$ and/or $\left[\begin{array}{ll}\tau_{L} & \varphi_{L}\end{array}\right] \neq\left[\begin{array}{ll}\tau_{H} & \varphi_{H}\end{array}\right]$, then talent and fameelasticities are heterogeneous across artist income quantiles.

Table 7 shows our estimates for Equation 9 with the equality tests for the estimated elasticities at the bottom of the table. Our results indicate that neither talent nor fameelasticities are uniform across quantiles ( $\mathrm{p}$-value $=0.036$ and $\mathrm{p}$-value $=0.006$ ), implying that the regression surfaces corresponding to each income quantile are not parallel. Specifically, as the single coefficients in the table show, the effect of talent on artist income is positive for all quantiles with increasing intensity, i.e., $\tau_{L}<\tau_{M}<\tau_{H}$. A similar result applies to fame (albeit its effect on low income artists is not significant), i.e., $\varphi_{L}<\varphi_{M}<\varphi_{H}$. Furthermore, Figure 2 shows that elasticities in the median and high income quantiles (in contrast with low income quantile) are similar to each other and to the elasticities estimated by OLS in Table 4 (represented by dashed lines). The evidence in Table 7 and Figure 2 suggests that Rosen's and Adler's hypotheses hold in high-median income quantiles but not for the low income quantile, where talent has a proportional effect on income $\left(\tau_{L} \cong 1\right)$ but fame has no effect $\left(\varphi_{L} \cong 0\right)$.

(1) $\tau_{L} \cong 1$ implies that in the low income quantile artists are not superstars and their income is proportional to their talent. However, there is a threshold of income (median income) beyond which Rosen's hypothesis holds.

(2) $\varphi_{L} \cong 0$ implies that fame plays no role in the low income quantile, so Adler's hypothesis does not hold. 
(3) The joint result $\tau_{L} \cong 1$ and $\varphi_{L} \cong 0$ implies that in the lower part of the income distribution, income and talent distributions are overlapping.

\subsection{Robustness checks}

We now present some sensitivity analyses and robustness checks. In Table 8 (columns 1-3), we regress artist income on talent (model 1), fame (model 2) and talent, fame and their interaction (model 3). The obtained results confirm those in Table 4 and add that the interaction between talent and fame, at least when using our proxies, is negligible. These findings suggest that the relationship between artist income and our measures of talent and fame is robust enough to withstand changes in the specification of the model.

A concern with our analysis is the risk of having chosen a poor fame proxy. For this reason, we perform a robustness check using two new and 'more conventional' proxies for fame. The first measure is based on the methodology in Garcia-del-Barrio and Pujol (2007) and creates a measure of fame based on the number of Google hits (fame-google) ${ }^{16}$; the second measure uses the reputation index provided by the artfacts.net website "which indicates the amount of attention each particular artist has received from art institutions' (fame-artfacts). The results of the regression models obtained using these additional proxies are presented in Table 8 (columns 4-9). These results suggest that our findings are robust to the choice of the fame proxy and that talent and fame might positively interact in influencing artist income. Although we cannot completely rule out the risk of having chosen a poor fame proxy, the risk does not seem strong enough to invalidate the conclusions of our work.

A further concern with our analysis is the potential problem of endogeneity of our proxies for fame: for example, it could be that fame is determined by income but not vice versa. Since in case of endogeneity, estimates are inconsistent, we perform endogeneity tests for each of our fame proxies following the two-step procedure described in Wooldridge (2010). To perform these endogeneity tests, we first need a variable that is related to fame and can be omitted from the income regression. The variable sculpture is a good candidate since it is reasonable to believe it is related to fame, but in all regression models (regardless of the chosen proxy for fame) it is not significant. The results of the endogeneity tests (one for each proxies for fame) do not reject the null hypothesis that fame is exogenous (fame-

\footnotetext{
16 This variable is based on the number of Google-hits that resulted by including in the search: "name of the artist' AND ‘art'. See Garcia-del-Barrio and Pujol, 2007 for additional details.
} 
factor-analysis $p$-value $=0.345$, fame-google $p$-value $=0.947$, fame-artfacts $p$-value $=0.515$ ) and suggests that, while we cannot exclude the problem of endogeneity in general terms, we can exclude it in the specific context of our analysis.

\section{Conclusions}

Using a unique hand collected dataset, which comprises all artwork sales in Italy between 2006 and 2010, we tested Rosen's and Adler's hypotheses using a plethora of econometric models on our dataset of modern and contemporary visual artists. Other empirical studies tested Rosen's and Adler's hypotheses for the music and sport sectors while we test Rosen's and Adler's hypotheses on the modern and contemporary visual art market and find that the differences in the level of talent and fame are reflected in artist income.

Our dataset allows us to extract new measures of artist talent and fame by means of a factor analysis: our measure of artist talent is positively associated with an artistic family environment, eclecticism and artistic studies; our measure of artist fame is found to be positively associated with death event and the number of years an artist (or her artwork) is present in the visual art market.

Using our proxies, we model artist factor income as a Cobb-Douglas function of talent and fame and estimate talent and fame-elasticities by OLS. The talent-elasticity is larger than one, implying a convex relationship between income and talent. This convex relationship is consistent with Rosen's hypothesis. The fame-elasticity is about one, implying a linear relationship between income and fame. This evidence offers support to Adler's hypothesis.

Using a SUR model, we evaluated the effects of our proxies for talent and fame on the average price and the number of artwork sales to understand their relative importance in generating artist income. The findings, based on our measures, show that about $3 / 4$ of the effects of talent and fame on an artist income pass through the number of artwork sales. A copula model shows that average prices and number of artwork sales exhibit a positive and asymmetric dependence relationship implying that they are likely to experience extreme low values together and are not likely to simultaneously realize upper tail values.

We split our sample in two subsamples, including artists prevalently traded in auction houses in the first subsample and artists prevalently traded in galleries in the second subsample. Then, we performed a poolability test. Our results indicate that a single 
encompassing model of artist income applies to all artists in our dataset and that Rosen's and Adler's hypotheses also continue to hold true at a disaggregated level. Thus, even though significant differences exist in the artist selection mechanisms and pricing strategies at auction houses and galleries, these differences do not affect the artist income generating process.

Furthermore, we estimated a simultaneous-quantile regression to test whether talent and fame-elasticities were uniform across income quantiles. Our results show that (consistent with Rosen) in low income quantiles artists are not superstars while Rosen's hypothesis only holds for artists with an income greater than the median level. In addition, our proxy for fame plays no role in low income quantiles.

Sensitivity analyses and robustness checks, which evaluate the appropriateness of our proxy for fame and its potential endogeneity, confirm the main findings of our analysis.

Our findings are important to understanding the mechanisms of superstar formation and implementing policies to support the income of talented artists who are not yet famous. Further empirical studies are needed to generalize our conclusions to other art forms and nonItalian markets. In addition, our findings also raise a few unanswered questions, which we cannot handle with our static cross section dataset, and open new avenues for future research: the measure of fame used in this study is time-invariant, but fame may indeed change over time. While we believe that in our sample and during the short time period we consider (five years), fame was sufficiently stable to produce reliable results, further empirical studies based on panel datasets may extend our conclusions considering time-varying determinants of income. In particular, panel datasets would make it possible to test dynamic implications that are only weakly identified in our static setting.

\section{References}

Adler M (1985) Stardom and talent. The American Economic Review 75: 208-212

Basilevsky AT (2009) Statistical factor analysis and related methods: Theory and applications. John Wiley \& Sons, New York

Baumol WJ, Throsby D (2012) Psychic Payoffs, Overpriced Assets, and Underpaid Superstars. Kyklos 65: 313-326 
Beatrice L (2012) Pop. L'invenzione dell'artista come star. Dalí, Warhol, Basquiat, Koons, Hirst, Cattelan. Rizzoli, Milan

Bonett DG, Price RM (2005) Inferential methods for the tetrachoric correlation coefficient. Journal of Educational and Behavioral Statistics 30: 213-225

Bryson A, Rossi G, Simmons R (2014) The Migrant Wage Premium in Professional Football: A Superstar Effect?. Kyklos 67: 12-28

Canals-Cerdá JJ (2012) The value of a good reputation online: an application to art auctions. Journal of Cultural Economics 36: 67-85

Candela G, Scorcu AE (1997) A price index for art market auctions. Journal of Cultural Economics 21: 175-196

Candela G, Scorcu AE (2012) Artist's resale right: Old issues and new problems. Umberto Allemandi \& Co, Turin

Castellani M, Pattitoni P, Scorcu AE (2012) Visual artist price heterogeneity. Economics and Business Letters 1: 16-22

Chamarbagwala R (2010) Economic liberalization and urban-rural inequality in India: a quantile regression analysis. Empirical Economics 39: 371-394

Cherubini U, Luciano E, Vecchiato W (2004) Copula methods in finance. John Wiley \& Sons, Chichester

Crain WM, Tollison RD (2002) Consumer choice and the popular music industry: A test of the superstar theory. Empirica 29: 1-9

Ekelund Jr RB, Ressler RW, Watson JK (2000) The "death-effect" in art prices: A demandside exploration. Journal of Cultural Economics 24: 283-300

Ehrmann T, Meiseberg B, Ritz C (2009) Superstar Effects in Deluxe Gastronomy - An Empirical Analysis of Value Creation in German Quality Restaurants. Kyklos 62: $526-541$

Etro F, Pagani L (2013) The market for paintings in the Venetian Republic from Renaissance to Rococò. Journal of Cultural Economics 37: 391-415

Filer RK (1990) Arts and academe: The effect of education on earnings of artists. Journal of Cultural Economics 14: 15-40

Filimon N, López-Sintas J, Padrós-Reig C (2011) A test of Rosen's and Adler's theories of superstars. Journal of Cultural Economics 35: 137-161

Franck E, Nüesch S (2008) Mechanisms of superstar formation in German soccer: Empirical evidence. European Sport Management Quarterly 8: 145-164 
Franck E, Nüesch S (2012) Talent and/or Popularity: What does it take to be a superstar?. Economic Inquiry 50: 202-216

Garcia-del-Barrio P, Pujol F (2007) Hidden monopsony rents in winner-take-all markets sport and economic contribution of Spanish soccer players. Managerial \& Decision Economics 28: 57-70

Genest C, Rémillard B, Beaudoin D (2009) Goodness-of-fit tests for copulas: A review and a power study. Insurance: Mathematics and Economics 44: 199-213

Ginsburgh VA, Throsby C (2006) Handbook of the economics of art and culture. NorthHolland, Amsterdam

Greene WH (2011) Econometric analysis, 7th ed. Prentice Hall, New York

Hagtvedt H, Hagtvedt R, Patrick VM (2008) The perception and evaluation of visual art. Empirical Studies of the Arts 26: 197-218

Hamlen WA (1991) Superstardom in popular music: Empirical evidence. The Review of Economics and Statistics 73: 729-733

Hamlen WA (1994) Variety and superstardom in popular music. Economic Inquiry 32: 395406

Hellmanzik C (2009) Artistic styles: revisiting the analysis of modern artists' careers. Journal of Cultural Economics 33: 201-232

Hellmanzik C (2013) Does travel inspire? Evidence from the superstars of modern art. Empirical Economics 45: 281-303

Joe $\mathrm{H}, \mathrm{Xu}$ JJ (1996) The estimation method of inference functions for margins for multivariate models. Technical Report 166, Department of Statistics, University of British Columbia

Kleiber C, Zeileis A (2008) Applied econometrics with R. Springer, New York

Koenker R (2005) Quantile regression. Cambridge. Cambridge University Press, New York

Koenker R, Hallock KF (2001) Quantile Regression. Journal of Economic Perspectives 15: $143-156$

Kozbelt A (2004) Originality and technical skill as components of artistic quality. Empirical Studies of the Arts 22: $157-170$

Krueger AB (2005) The economics of real superstars: The market for rock concerts in the material world. Journal of Labor Economics 23: 1-30

Lehmann EE, Schulze GG (2008) What does it take to be a star? - The role of performance and the media for German soccer players. Applied Economics Quarterly 54: 59-70 
Lucifora C, Simmons R (2003) Superstar effects in sport evidence from Italian soccer. Journal of Sports Economics 4: 35-55

MacDonald G (1988) The economics of rising stars. American Economic Review 78: 155166

Mc Andrew C (2010) TEFAF art market report 2013: the international art market 2007-2009 trends in the art trade during global recession. TEFAF, Maastricht

Nelsen RB (2006) An introduction to copulas. Springer, New York

Olsson U (1979) Maximum likelihood estimation of the polychoric correlation coefficient. Psychometrika 44: 443-460

Patuelli R, Vaona A, Grimpe C (2010) The German East-West divide in knowledge production: an application to nanomaterial patenting. Tijdschrift voor Economische en Sociale Geografie 101: 568-582

Rengers M, Velthuis O (2002) Determinants of Prices for Contemporary Art in Dutch Galleries, 1992-1998. Journal of Cultural Economics 26: 1-28

Rosen S (1981) The economics of superstars. The American Economic Review 71: 845-858

Sklar A (1959) Fonctions de répartition à n dimensions et leurs marges. Publ. Inst. Statist. Univ. Paris 8: 229-231

Thompson D (2010) The \$12 million stuffed shark: The curious economics of contemporary art. Palgrave Macmillan, New York

Throsby D (2006) An artistic production function: theory and an application to Australian visual artists. Journal of Cultural Economics 30: 1-14

Towse R (2006) Human capital and artists' labour markets. In: Ginsburg VA, Throsby D (ed) Handbook of the Economics of Art and Culture, vol. 1. Elsevier, Amsterdam, pp. 865-894

Towse R (2013) A handbook of cultural economics. Edward Elgar Publishing, Cheltenham

Trivedi PK, Zimmer DM (2007) Copula modeling: An introduction for practitioners. Now Publishers Inc, Hanover

Ursprung HW, Wiermann C (2011) Reputation, price, and death: an empirical analysis of art price formation. Economic Inquiry 49: 697-715

Verbeek M (2012) A guide to modern econometrics, 4th ed. Wiley, Chichester

Wooldridge JM (2010) Econometric analysis of cross section and panel data, 2nd ed. MIT press, Cambridge

Zellner A (1962) An efficient method of estimating seemingly unrelated regressions and tests for aggregation bias. Journal of the American Statistical Association 57: 348-368 
Table 1 Descriptive statistics (variables are in levels)

\begin{tabular}{c|cccc}
\hline Variable & Mean & Std. Dev. & Min & Max \\
\hline$Y$ & 791,169 & $2,202,502$ & 6,500 & $33,800,000$ \\
$P$ & 18,031 & 28,553 & 3,167 & 376,077 \\
$N$ & 29 & 52 & 2 & 418 \\
\hline deceased & $44.36 \%$ & & & \\
existence & 81.41 & 28.14 & 27 & \\
descendant & $5.45 \%$ & & & \\
muforms & $71.27 \%$ & & & \\
study & $71.09 \%$ & & & \\
gallery & $54.88 \%$ & $32.21 \%$ & & \\
male & $95.64 \%$ & & & \\
sculpture & $11.09 \%$ & & & \\
world & $29.82 \%$ & & & \\
$1850-1875$ & $3.64 \%$ & & & \\
$1875-1900$ & $20.00 \%$ & & & \\
$1900-1925$ & $17.27 \%$ & & \\
$1925-1950$ & $15.82 \%$ & & & \\
$1950-1975$ & $23.45 \%$ & & & \\
$1975-2000$ & $19.82 \%$ & & & \\
\hline
\end{tabular}

Table 2 Polychoric correlation matrix

\begin{tabular}{c|ccccc}
\hline variable & deceased & descendant & existence & muforms & study \\
\hline deceased & 1 & & & & \\
descendant & 0.194 & 1 & & & \\
existence & 0.928 & 0.141 & 1 & & \\
muforms & 0.137 & 0.135 & 0.104 & 1 & \\
study & 0.021 & 0.084 & 0.018 & 0.127 & 1 \\
\hline
\end{tabular}


Table 3 Rotated (oblique promax) factor loadings (pattern matrix) and unique variances

\begin{tabular}{c|cc|c}
\hline variable & Factor 1 & Factor 2 & Uniqueness \\
\hline deceased & 0.978 & & 0.043 \\
existence & 0.980 & & 0.053 \\
descendant & & 0.523 & 0.668 \\
muforms & & 0.675 & 0.534 \\
study & & 0.704 & 0.516 \\
\hline
\end{tabular}

Blank if the absolute value of a loading is less than 0.2

Table 4 Regression models

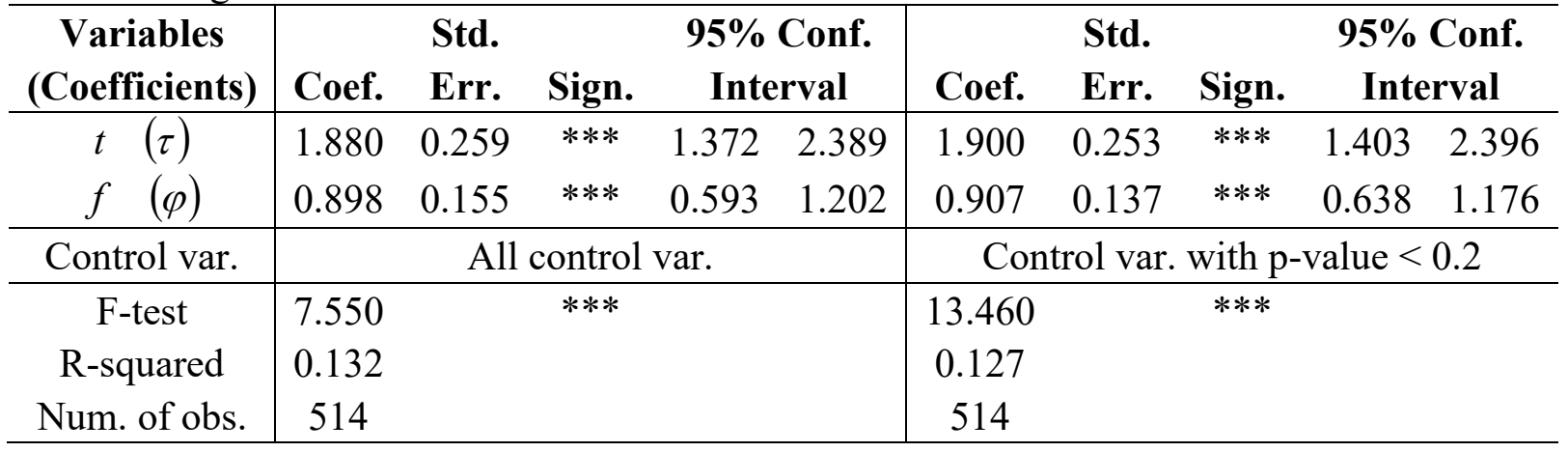

Significance codes: $* * * 0.01, * * 0.05, * 0.10$. Robust standard errors. Control variables include gallery, male, sculpture, world and period dummies.

Table 5 SUR model

\begin{tabular}{|c|c|c|c|c|c|c|c|c|}
\hline Equation & \multicolumn{4}{|c|}{$p$} & \multicolumn{4}{|c|}{$n$} \\
\hline $\begin{array}{c}\text { Variables } \\
\text { (Coefficients) }\end{array}$ & Coef. & $\begin{array}{l}\text { Std. } \\
\text { Err. }\end{array}$ & Sign. & $\begin{array}{l}\text { 95\% Conf. } \\
\text { Interval }\end{array}$ & Coef. & $\begin{array}{l}\text { Std. } \\
\text { Err. }\end{array}$ & Sign. & $\begin{array}{l}\text { 95\% Conf. } \\
\text { Interval }\end{array}$ \\
\hline$t \quad(\tau)$ & 0.444 & 0.141 & $* * *$ & $\begin{array}{ll}0.167 & 0.720\end{array}$ & 1.437 & 0.215 & $* * *$ & $1.016 \quad 1.858$ \\
\hline$f \quad(\varphi)$ & 0.217 & 0.084 & $* * *$ & $0.052 \quad 0.381$ & 0.681 & 0.128 & $* * *$ & $0.430 \quad 0.932$ \\
\hline Control var. & \multicolumn{4}{|c|}{ All control var. } & \multicolumn{4}{|c|}{ All control var. } \\
\hline$\sigma_{p n} /\left(\sigma_{p} \sigma_{n}\right)$ & 0.261 & & $* * *$ & & & & & \\
\hline Wald-test & 96.5 & & $* * *$ & & 126.9 & & $* * *$ & \\
\hline R-squared & 0.158 & & & & 0.198 & & & \\
\hline Num. of obs. & 514 & & & & 514 & & & \\
\hline
\end{tabular}


Table 6 Regression models for artists prevalently traded in auction houses and for artists prevalently traded in galleries

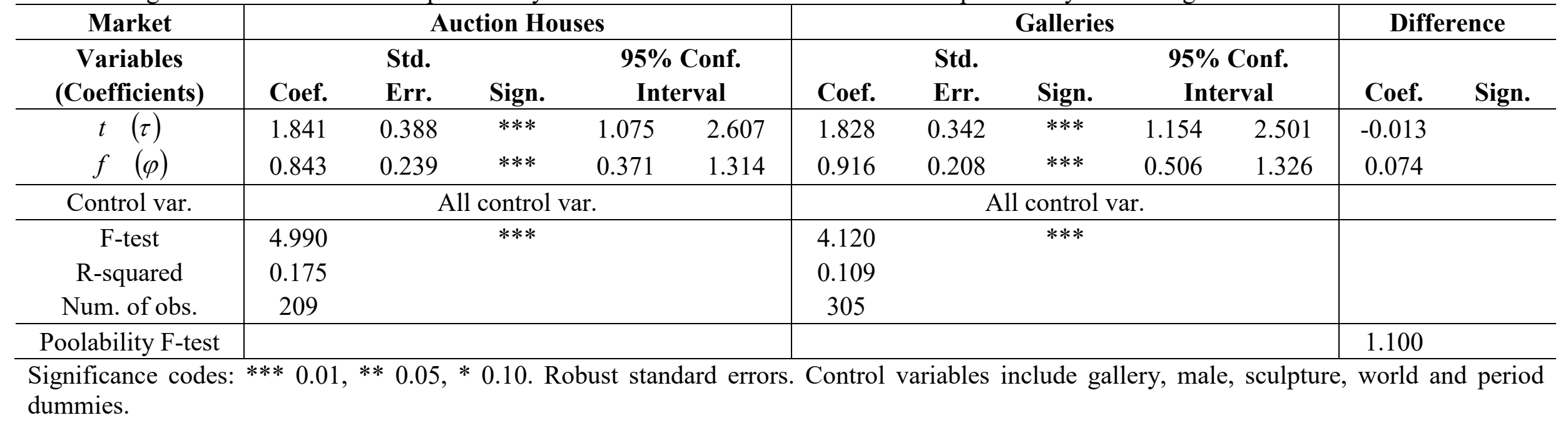

Table 7 Simultaneous-quantile regression

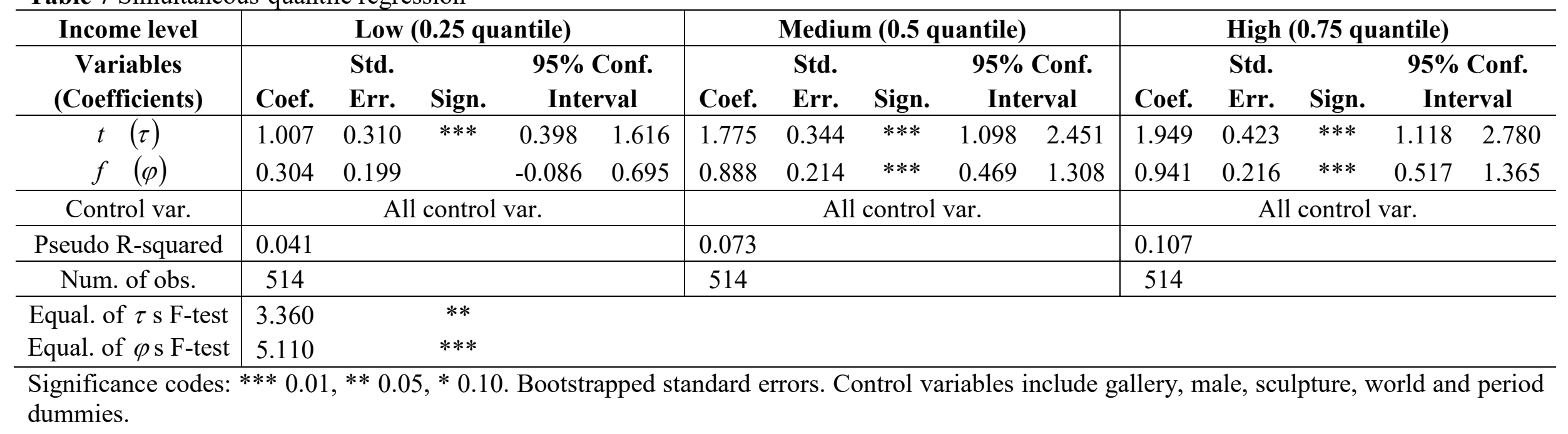


Table 8 Robustness checks

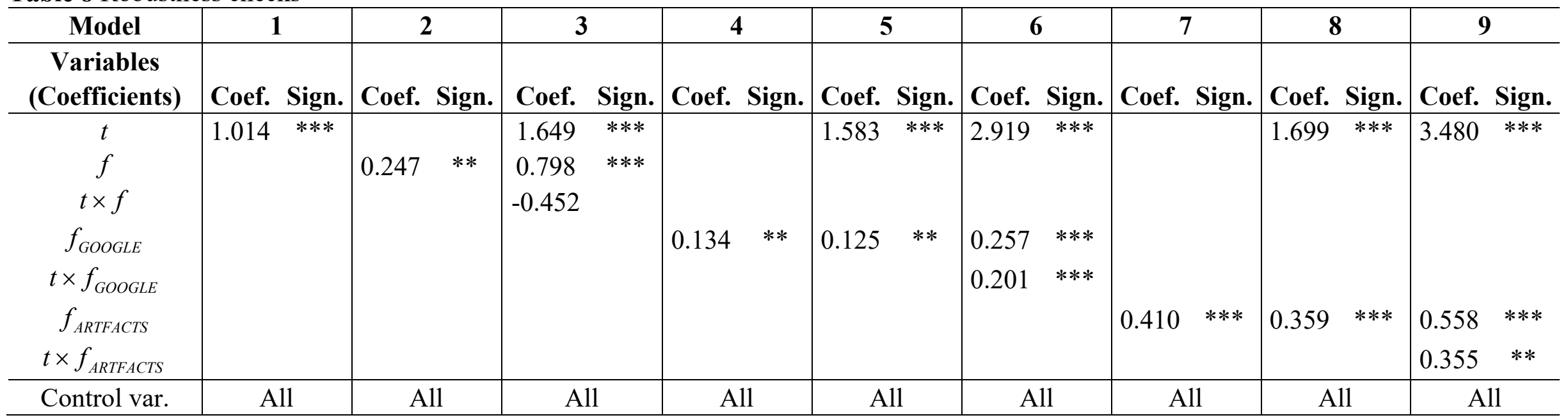

Significance codes: $* * * 0.01, * * 0.05, * 0.10$. Robust standard errors. Control variables include gallery, male, sculpture, world and period dummies. 

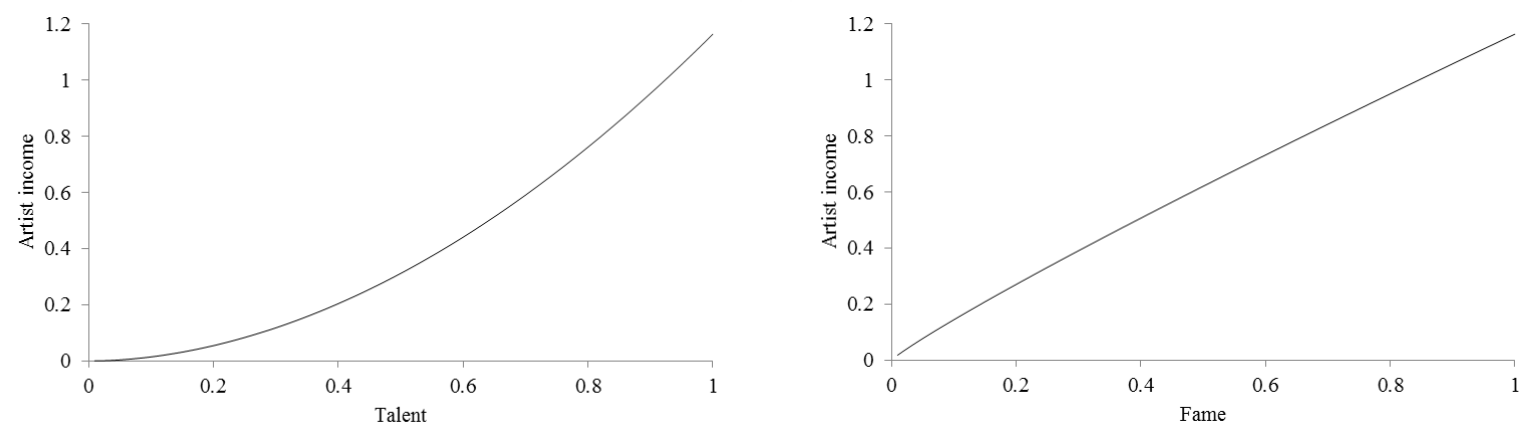

Fig. 1 Effects of talent (left plot) and fame (right plot) on average artist income (mln $€$ ).
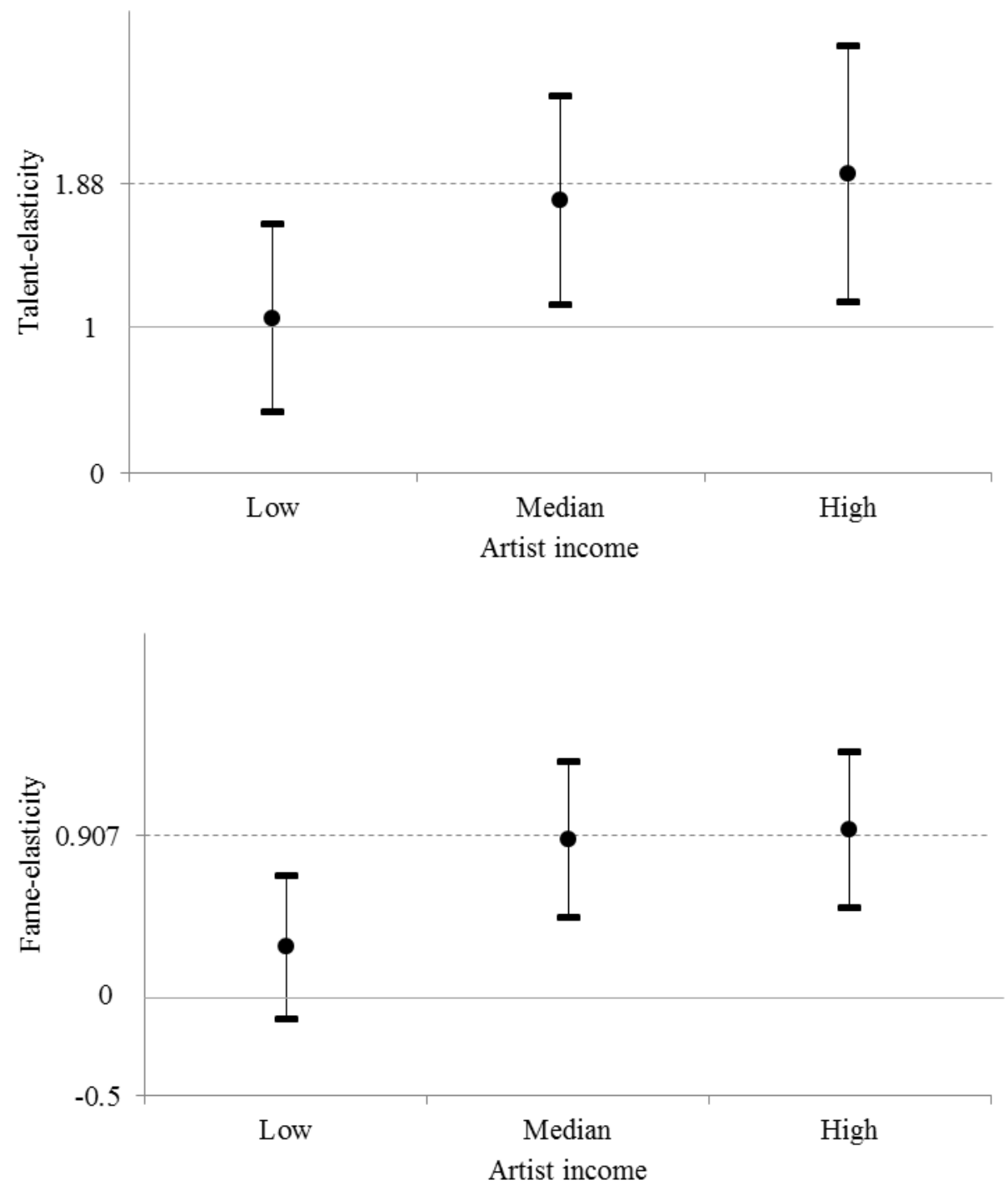

Fig. 2 Talent and fame-elasticities for varying quantiles $(\mathrm{Low}=0.25$, Median $=0.5$, High $=$ 0.75). Elasticities estimated by OLS are represented by dashed lines. 